\title{
The seaward limit of wave effects on coastal macrobenthos
}

\author{
Werner Armonies · Christian Buschbaum • \\ Monika Hellwig-Armonies
}

Received: 5 March 2013/Revised: 18 June 2013/Accepted: 21 June 2013/Published online: 16 July 2013

(C) Springer-Verlag Berlin Heidelberg and AWI 2013

\begin{abstract}
Exposed sandy coasts are predominantly physically controlled environments where benthic communities are structured by the independent response of species to the physical environment, with minimal biological interactions (swash exclusion hypothesis). This prevalence of physical control may be regarded as a typical property of exposed coastal areas. In an offshore direction, the importance of wave effects on the benthos will diminish until a depth is reached where they are no longer significant [wave exclusion hypothesis (WEH)]. This loss of a coastal property may be used to define an offshore depth limit of the coastal zone. We used a large set of benthos data from the SE North Sea to test whether an offshore limit of the coast can be clearly recognised despite strong small-scale variability and how this limit would vary seasonally and from year to year. In accordance with WEH, both species density and total abundance of macrobenthos were low in the surf zone, strongly increased with depth, and averaged over all sampling dates became relatively constant below $30 \mathrm{~m}$ depth. Seasonally, these gradients were weaker during summer recruitment than during autumn. Species richness, by contrast, showed no significant difference with depth. In single years, the depth of the turning point from increasing abundances to constant abundances varied between 20 and $31 \mathrm{~m}$ (equivalent to $40-80 \mathrm{~km}$ off the coastline) depending on wave height. We
\end{abstract}

Communicated by H.-D. Franke.

W. Armonies $(\bowtie) \cdot$ C. Buschbaum · M. Hellwig-Armonies Alfred-Wegener-Institut Helmholtz-Zentrum für Polar- und Meeresforschung, Wattenmeerstation Sylt, Hafenstr. 43, 25992 List, Germany

e-mail: werner.armonies@awi.de conclude that this zone can be derived from benthic community gradients.

Keywords Coast - Benthos - Diversity - Depth - Waves . Disturbance

\section{Introduction}

Coastal benthic communities are structured by both physical conditions and biological interactions. Where the physical conditions are rather benign, biological interactions are likely to control the community structure, and vice versa. Among the physical factors, wave effects and currents dominate the disturbance process of the seabed. Sediment mobility is caused by waves and wind-driven currents (Warner et al. 2012) with waves being more important on the inner shelf and energetic currents on the outer shelf (Ulses et al. 2008). Quantitatively, the importance of sediment disturbance depends on wave climatology, local topography, wave exposure and sediment type (Hall 1994). Exposed sandy beaches are on the mainly physically controlled side of the spectrum where communities are structured by the independent response of species to the physical environment, with minimal biological interactions (swash exclusion hypothesis, McLachlan et al. 1984; McLachlan 1990). In the surf zone next to the beach, the seabed is rather mobile (Brown and McLachlan 1990) and macrobenthic diversity attains a minimum (Janssen et al. 2008). With decreasing wave energy, sandy beach communities increase in richness, density, total abundance and biomass (Defeo and McLachlan 2005). Comparable increases are expected from the surf zone of reflective beaches with increasing water depth until a depth is reached, where wave effects on the benthos are no longer 
significant (wave exclusion hypothesis (WEH); Paavo et al. 2011).

The observation that shallow-water species were a subset of deeper living species led to the idea of a single species source pool serving reflective and dissipative shorelines, with species being excluded by harsh conditions in reflective environments (McLachlan et al. 1984; McLachlan 1990). Apart from possible problems of larvae to reach the sediment in turbulent waters, recruitment limitation may not be the dominant determinant of spatial and temporal patterns in soft-sediment benthos, but postsettlement processes play a significant role in population regulation and community organisation (Olafsson et al. 1994). These post-settlement processes include a number of wave-induced processes such as inadvertent resuspension and removal of organisms as well as physical damage to the organisms during sediment disturbance (Paavo et al. 2011). But, waves also affect the sedimentary environment, including sediment stability and grain size composition (Le Hir et al. 2000). Grain size in turn co-varies with sedimentary organic matter, pore-water chemistry, and microbial abundance and composition (Snelgrove and Butman 1994). Therefore, wave-induced sediment disturbance causes changes in many aspects of the benthic environment, and hydrodynamics certainly is a super-factor on the continental shelves.

The effects of hydrodynamic sediment disturbance are likely to change with water depth. Small waves can only affect the sediment in shallow waters, and increasingly larger waves are needed to significantly affect the fauna and sediment in greater depths. Since large waves usually only occur during storm events, this means a change from periodic disturbance in the shallows to episodic disturbance in greater depth. We accordingly expect a correlation of faunal composition with extreme weather events in larger depth but not necessarily in shallow waters. In addition, the susceptibility of single benthic specimens to hydrodynamic sediment disturbance may vary over time because the body condition, susceptibility to mechanical damage and position in the sediment may all change seasonally. Therefore, the quantitative effect on the benthos brought about by a storm event may vary seasonally.

However, the fauna is not only subject to environmental disturbance, but the organisms themselves may affect sediment properties. The increase in benthos abundance and species richness with increasing depth predicted by the WEH results in an increasing potential for biological control of sediment characteristics with depth (Snelgrove and Butman 1994). Spatially, storm effects may vary at small scales between sites dominated by sediment stabilising or destabilising species and this is likely to increase the variability (patchiness) in faunal composition (Borsje et al. 2008; Gray 2002; Ramey et al. 2009).
This patchiness has important implications for comparative and descriptive studies of distribution and abundance because it complicates comparisons of abundance at larger spatial scales (Morrisey et al. 1992). To overcome the problems associated with strong patchiness, Morrisey et al. (1992) proposed pilot studies to identify scales at which variation is significant. However, dealing with an assemblage of several hundred species, it is highly unlikely to find any spatial scale without significant spatial variation in some of the species. An alternative to deal with patchy distributions is collecting samples from a high number of sites, with appropriate spatial and temporal replication, though at high cost for both shipping time and sample analyses. This may be the reason why the coastal gradient of benthic community structure outlined above has been repeatedly proposed but rarely demonstrated. We used a large data set primarily designed to analyse the spatial variability in benthic populations over years (about 100 stations, with 3 spatial and 12 temporal replicates) from the southeastern North Sea to check whether these coastal gradients of benthos abundance, species richness and species composition really exist.

\section{Materials and methods}

\section{Study site and sampling}

In order to reveal the benthic zonation patterns as general as possible, we studied a large plot of some $8,000 \mathrm{~km}^{2}$ in the south-eastern North Sea between $54^{\circ} 10^{\prime} \mathrm{N}$ and the German-Danish border (on average $110 \mathrm{~km}$ ) and from $007^{\circ} \mathrm{E}$ to $008^{\circ} 10^{\prime} \mathrm{E}$ (approximately $75 \mathrm{~km}$ ). Within that area, 101 sampling stations were arranged in a regular grid with a longitudinal distance between stations of $10^{\prime}$ (approximately $11 \mathrm{~km}$ ) and a latitudinal distance of $05^{\prime}$ (approximately $9 \mathrm{~km}$, Fig. 1). In the east, a chain of barrier islands separates the study area from the Wadden Sea.

The sediments in the study area are affected by both waves and currents. The currents component does not differ significantly during the calm and the storm periods and shows permanent resuspension zones mainly in the shallowest $(<10 \mathrm{~m})$ part of the study area while the wave component depends upon storm intensity and wind direction (Dobrynin et al. 2010). With respect to sediment stability and the orientation of newly emerging bedforms, the study area can be characterised as a storm-dominated environment (Diesing et al. 2006). A model indicates that mean shear stress velocity enables resuspension of particulate matter over all of the study areas during storm periods and down to approximately $10 \mathrm{~m}$ during calm periods (Dobrynin et al. 2010). 
Fig. 1 Arrangement of sampling sites in the SE North Sea. Filled rectangles denote regularly sampled sites and open rectangles occasionally sampled stations. Sampling stations in the surf zone west of the island of Sylt (cruises 'Oland A' and 'Oland B') not indicated

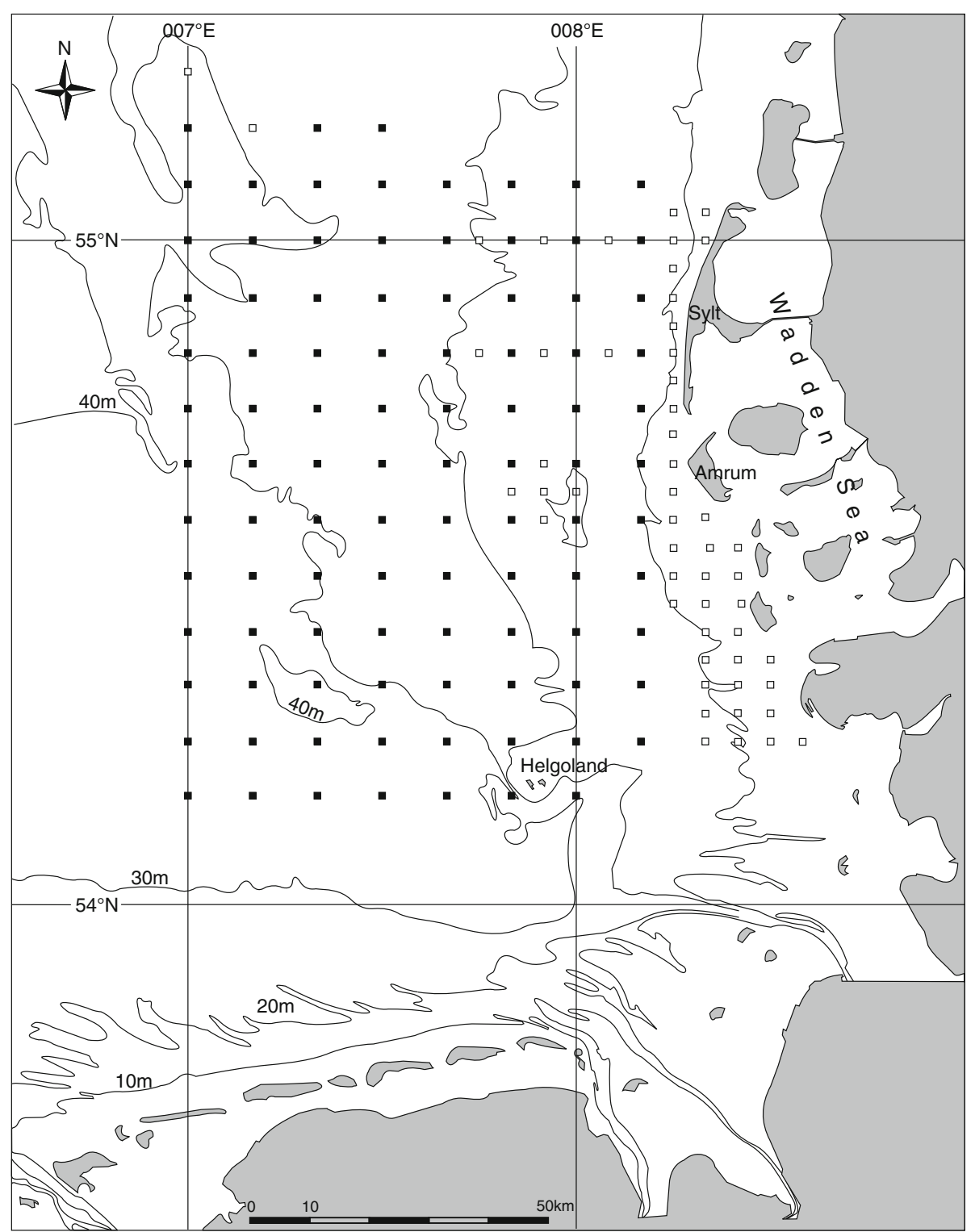

During each of the sampling periods (Table 1), three replicate sediment cores $\left(0.02 \mathrm{~m}^{2}\right.$ box corer $)$ were collected from each of the sampling stations. To avoid 'pseudoreplication' (Hulbert 1984), the replicates must be some distance apart to prevent underestimates of variability. From a study in Scottish sea-lochs (similar depth, similar sediment types and similar latitude as the present study), Somerfield and Gage (2000) proposed a minimum distance of 40-100 m. We adapted to that recommendation by allowing for a navigational deviation from the target position of $0.1 \mathrm{~nm}$ and by allowing for a slight drift of the ship during sample collection. On an average, the ship stopped $100 \mathrm{~m}$ before the station target (or behind, depending on wind conditions and tidal currents) and drifted across the sampling station during sample collection. This resulted in an average distance between replicate cores of $52 \mathrm{~m}$ (GPS navigation; position, depth and nautical parameters were automatically recorded for each sediment core) and in an average distance of individual cores from the target position of $100 \mathrm{~m}$, i.e. roughly $1 \%$ of the distance to the neighbouring sample station. The sampled sediment depth varied between $5 \mathrm{~cm}$ in densely packed fine sand (smaller cores were rejected) and a maximum of $30 \mathrm{~cm}$ in coarse sand (capacity limit of the box).

During two sampling periods, stormy weather prevented us from reaching all of the sampling stations (Table 1). Large stones prevented regular sampling in two stations of the regular grid, and one station became disturbed by sand extraction during this study. These stations were excluded from this analysis. Additional samples from shallow waters (2-10 m depth) east of the regular sampling grid were 
Table 1 Sampling periods

\begin{tabular}{lllllc}
\hline Cruise ID & Date/start & Date/end & $\begin{array}{l}\text { No. of } \\
\text { stations } \\
\text { visited }\end{array}$ & $\begin{array}{l}\text { No. of cores } \\
\text { collected }\end{array}$ & Remarks \\
\hline HE206 & 24.04 .2004 & 27.04 .2004 & 104 & 309 & Pilot sampling \\
HE218 & 12.09 .2004 & 17.09 .2004 & 48 & 144 & $\begin{array}{c}\text { Northern stations } \\
\text { missing }\end{array}$ \\
HE241 & 10.10 .2005 & 14.10 .2005 & 99 & 297 & \\
HE255 & 17.07 .2006 & 21.07 .2006 & 99 & 297 & \\
HE258 & 23.08 .2006 & 26.08 .2006 & 99 & 297 & \\
HE262 & 25.09 .2006 & 28.09 .2006 & 99 & 297 & 297 \\
HE272 & 02.07 .2007 & 05.07 .2007 & 99 & 297 & \\
HE275 & 17.08 .2007 & 20.08 .2007 & 99 & 297 & Eastern \\
HE278 & 18.09 .2007 & 23.09 .2007 & 99 & 297 & enlargement \\
HE293 & 08.09 .2008 & 11.09 .2008 & 99 & 297 & Eastern \\
HE311 & 06.09 .2009 & 09.09 .2009 & 99 & 105 & enlargement \\
Oland A & 05.08 .2009 & 05.08 .2009 & 35 & 321 & Western stations \\
missing \\
Oland B
\end{tabular}

collected during cruises 'Oland C' and 'Oland D' between the grid and the islands of Sylt and Amrum, respectively, and 'Oland A' and 'Oland B' in the surf zone west of the island of Sylt. During the latter cruises, the sampling stations were very close to each other (cross-shore distance approximately $100 \mathrm{~m}$, long-shore distance approximately $500 \mathrm{~m}$ ). Therefore, the replicate cores had an average distance of 5-10 m only.

Water depth varied between 10 and $50 \mathrm{~m}$ in the regular sampling grid and between 10 and $2 \mathrm{~m}$ in the 'eastern enlargement' stations. However, since $>45 \mathrm{~m}$ depth was represented by two stations only, we restrict the graphical presentation of the data to a maximum of $45 \mathrm{~m}$. Concerning the faunal composition, most of the studied area can be classified with a fine sand Tellina fabula association locally interspersed with a Goniadella-Spisula association in patches (glacial relicts) of coarse sand (Salzwedel et al. 1985). Only in the southernmost part, the fauna passes into an Amphiura filiformis association (muddy very fine sand south-west of Helgoland Island) and into a Nucula nitidosa association (clayey silt south-east of Helgoland; Salzwedel et al. 1985). Details of the sediment composition can be found at www.gdi.bsh.de/mapClient/initParams.do.

Sample treatment on board followed an identical protocol for all cruises and ships. Once retrieved, the sediment was transferred into a bucket, fine particles were allowed to settle for approximately $1 \mathrm{~min}$ until the supernatant water was poured through $1-\mathrm{mm}$ meshes, and the sediment core was weighted to the nearest $0.1 \mathrm{~kg}$ (wet weight of the sediment). Then the sediment was sieved through 1-mmsquare meshes and the remainder fixed in $5 \%$ buffered formaldehyde solution. During all cruises except Oland A and Oland B (Table 1), the granulometric sediment composition was analysed for every single core collected. This was done by subsampling (approximately $100 \mathrm{~g}$ wet weight) the sediment that had passed the sieve for later mechanical dry sieving (mesh sizes 500, 250, 125 and $62 \mu \mathrm{m}$ and a pan). The sediment fraction $>1 \mathrm{~mm}$ (included in the faunal samples) was quantified as wet weight after sorting of the fauna.

The fauna was identified to species level if possible. However, when only adults of a genus could be determined to species level while juveniles numerically dominated, it was decided to pool all individuals and treat them on a genus level (e.g. species of the genera Nephtys and Spio). Therefore, the estimates of species density and species richness are rather conservative.

\section{Statistical analyses}

The focus of this paper is to describe the patterns of benthic community structure along a depth gradient. This includes 
abundance of total infauna and of major taxa, species richness and the change in species composition along the depth gradient. Since abundance varied between $<10$ and $>10^{5} \mathrm{~m}^{-2}$, all abundance data were log-transformed prior to the analyses.

For comparing species richness among sites, two aspects need to be considered, species density (the number of species per unit area) and how species richness varies with the number of individuals sampled (Gotelli and Colwell 2001). Species density in this study always refers to the original sampling units, i.e. box cores of $0.02 \mathrm{~m}^{2}$ surface area and a depth of $5-30 \mathrm{~cm}$ depending on sediment penetrability. Species richness is described as the number of species in an assemblage of $1,000,5,000$ or 10,000 individuals. One possible way to calculate these species numbers is rarefaction from the samples of pre-defined depth intervals (Gotelli and Colwell 2001), yielding a single estimate for each depth interval. In order to exploit all available data, we used an alternative method by arranging the samples in order for increasing water depth (with a random order of samples from equal depth) and then joining as many consecutive cores as were needed to get a number of individuals as close as possible to $1,000(5,000$ or 10,000$)$. Joining always started with the shallowest sampling sites and proceeded to greater depth. The number of species recorded in these groups is our estimate of species richness. The related depth was represented by the mean depth of the joined cores. Besides species richness, Shannon-Wiener diversity $\mathrm{H}^{\prime}$ was calculated from the same groups.

The change in species composition was studied by comparing the spectrum of species found in $<40 \mathrm{~m}$ depth to the following stations arranged in 5-m depth intervals. The last record of a species along the depth gradient is termed a loss and the first one a gain of a species. Multidimensional scaling (MDS) was used to detect the internal structure of the species assemblage based upon a correlation matrix of species abundance. For computing, we condensed this matrix to the species with a presence of more than $2 \%$, i.e. which occurred in at least 85 of the sediment cores.

The above analyses included all data according to Table 1 to represent the most general case (i.e. an average over many years). In order to investigate seasonal differences or differences between years, some of the analyses were repeated for different subsets of the data, as indicated in the respective legends.

The high number of sampled cores $(>4,000)$ causes some problems with the graphical representation of data. On the one hand, such a number of points is difficult to picture. On the other hand, the high small-scale (withinsite) variability yields rather wide clouds of data points. We therefore calculated means and confidence intervals for pre-defined depth classes and show these means instead of the original data. To find a general trend, we used distance- weighted least-squares fitting (StatSoft 1994). This method does not fit a pre-defined function to the data but produces a curve of means along many sections of the $x$-axis, with the weight of each data point decreasing with its distance from the respective section analogous to a moving average. This is done by calculating a polynomial (second-order) regression for each value on the $X$ variable scale to determine the corresponding $Y$ value such that the influence of individual data points on the regression (i.e. the weight) decreases with their distance from the particular $X$ value (StatSoft 1994). For the weight function, we used the STATISTICA $^{\mathrm{TM}}$ standard settings $(s=0.25)$.

The high number of samples also influences ANCOVA and correlations because non-significant $(p>0.05)$ results are rare exceptions. Therefore, the importance of an effect must be estimated by the $r^{2}$ instead of the p levels. Accordingly, the main purpose of these statistics is to check for the relative impact of various factors as estimated by partial etasquares. These give the ratio of variance (sum of squares) accounted for by an effect and the total variance (total of all sums of squares for all effects, interactions and errors).

During most sampling periods, we found increasing abundance of individuals from the shallows to deeper water until abundance reached rather constant levels in the greatest depths. To determine at which depth the increase in abundance in the shallows passed into the relatively constant level in greater depth, we calculated one-way ANOVAs with abundance (species density) as the independent variable and depth class as a fixed factor and used post hoc Tukey's HSD test to identify significant differences between the depth classes. From these, the 'constant level in greater depth' was determined as the depth classes from the greatest depth to the last depth class with no significant difference in abundance or species density among all depth classes of that cluster. The lowest water depth included in that cluster is further on called the coastal depth limit. There are two possible ways of forming the depth classes. The first is to attach the samples to pre-defined depth intervals with a variable number of samples included in each depth class. This resulted in some classes with a very low number of samples and accordingly a low power to detect significant differences between them. Therefore, we used the alternative method in pre-defining the number of samples per depth class (in our case arbitrarily set to 20) with a variable width of the depth interval. In practice, we arranged the samples in order for increasing water depth and then split this order into groups of 20 samples each. The last class in some cases deviated from the number of 20 samples (from 17 to 24), but we nevertheless assume that this kind of classification strongly improved the power to detect statistically significant differences between classes.

To test for correlations between the coastal depth limit and wave intensity, we used the data from a waverider buoy west 
of the island of Sylt $\left(55^{\circ} 55^{\prime} \mathrm{N}, 008^{\circ} 13.30^{\prime} \mathrm{E}\right.$, water depth $13 \mathrm{~m}$ ). Among the recorded variables, we selected significant wave height (the average height of the highest third of the waves) based on hourly records. For the months June (estimated start of larval recruitment to the sediment), July and August, we counted the number of hours with a significant wave height $>2,>2.5$ and $>3 \mathrm{~m}$, which represents exceptionally high waves during the rather calm summer months. These counts were correlated with the coastal depth limit as estimated from ANOVA (see above). However, we will consider these correlations very carefully because the data of a single buoy may not be representative of an $8,000 \mathrm{~km}^{2}$ study area and because the wave heights of 2, 2.5 and $3 \mathrm{~m}$ were arbitrarily selected while small specimens living in superficial sediment layers might be affected by much smaller waves. In addition, the degree of sediment disturbance needed to affect the fauna may change seasonally. Finally, these correlations were computed for the autumn (September and October) samples of the years 2004-2011 ( $n=8$ ); hence, the data basis is relatively weak with a low statistical power.

\section{Results}

\section{Abundance}

Considering all sampling periods together to represent the most general case, mean abundance of macrobenthos increased continuously from the shallows to a water depth of some $30 \mathrm{~m}$ and then remained rather constant (Fig. 2, bottom right). Due to the high number of cores, the mean abundances in depth classes have narrow confidence limits despite strong variance in the data. Hence, an ANCOVA explained $43 \%$ of the variance in abundance as temporal (cruise), large-scale spatial (depth effect) or related to sediment composition (Table 2) but left $57 \%$ of small-scale spatial variance unexplained. Among the tested variables, date (cruise) and water depth explained most of the variability and sediment composition (median diameter of sand grains) the least (Table 2, eta-squared).

An increase in abundance with increasing water depth occurred in all autumn (September or October) samples, but the steepness of increase and the coastal depth limit varied over years (between $20 \mathrm{~m}$ in September 2010 and $31 \mathrm{~m}$ in September 2004 and October 2005, Fig. 2). Over time, the autumn coastal depth limit (as estimated from abundance) correlated positively with the frequency of waves $>3 \mathrm{~m}$ in June, i.e. during the main settlement period $\left(r^{2}=0.53\right.$, $n=8, t=2.6109, p<0.040$ ).

In 2006 and 2007 with three sampling periods each, seasonal variations were statistically significant (Table 3) but not very marked (Fig. 3). However, July 2006 was a remarkable exception with high abundance (particularly of juveniles) in shallow waters (Fig. 3 and significant year $\times$ month interaction term in Table 3 ). Compared to July 2006, the abundance in August 2006 dropped by an order of magnitude in $10 \mathrm{~m}$ depth but remained fairly constant between 20 and $30 \mathrm{~m}$ depth.
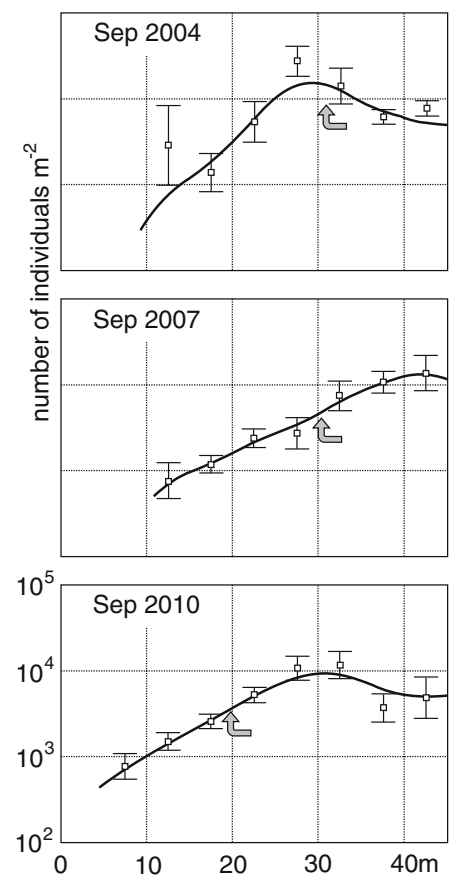
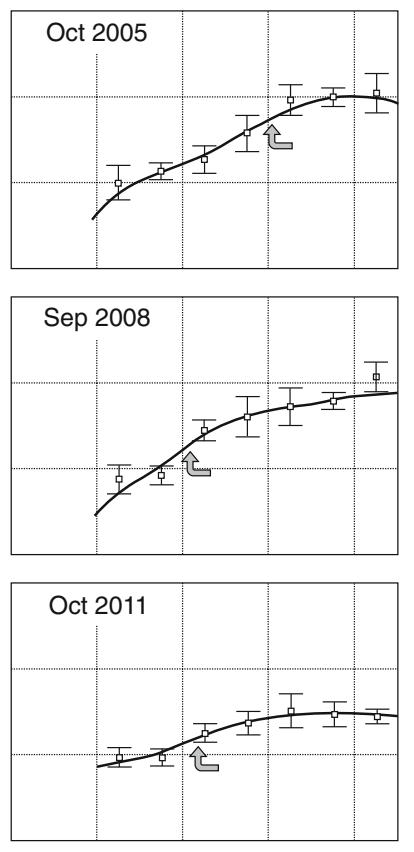

water depth
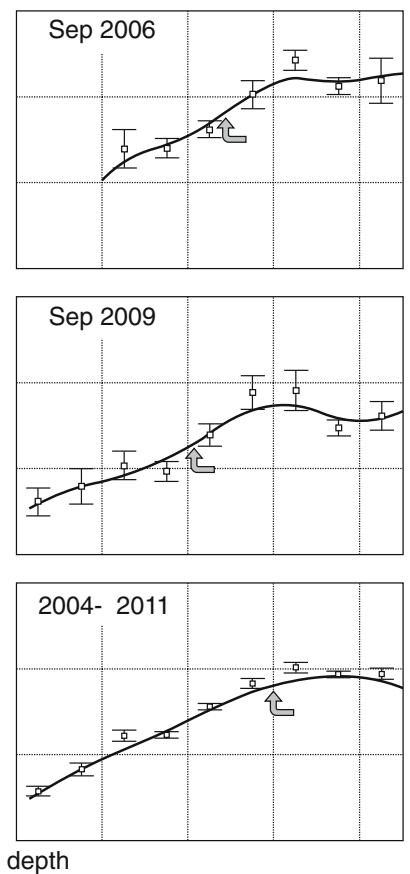

Fig. 2 Macrobenthos abundance in the coastal depth gradient in autumn 2004-2011; mean $\pm 95 \%$ confidence intervals (horizontal bars) and distance-weighted least squares (line). Arrows indicate the coastal depth limit as estimated by ANOVA 
Table 2 ANCOVA of benthos abundance depending on water depth, cruise and median diameter of sand grains (sediment md); all sampling periods except cruises Oland A and B

\begin{tabular}{lrrrrrr}
\hline Effect & $\begin{array}{l}\text { Sum of } \\
\text { squares }\end{array}$ & \multicolumn{1}{l}{$\begin{array}{l}\text { Mean } \\
\text { square }\end{array}$} & \multicolumn{1}{l}{$l$} & \multicolumn{1}{l}{$p$} & $\eta^{2}$ \\
\hline Constant & $1,849.82$ & 1 & $1,849.82$ & $8,437.32$ & 0.0000 & 0.5892 \\
$\begin{array}{l}\text { Water } \\
\text { depth }\end{array}$ & 147.34 & 1 & 147.34 & 672.03 & 0.0000 & 0.0469 \\
$\begin{array}{l}\text { Sediment } \\
\text { md }\end{array}$ & 52.75 & 1 & 52.75 & 240.59 & 0.0000 & 0.0168 \\
Cruise & 271.92 & 12 & 22.66 & 103.36 & 0.0000 & 0.0866 \\
Error & 817.55 & 3,729 & 0.22 & & & 0.2604 \\
\hline
\end{tabular}

Cruise represents both temporal effects (year and month of sampling) and deviations in the number of sampled stations (see Table 1). Model multiple $R^{2}=0.4268$

\section{Abundance in major taxa}

Increases in abundance with depth also occurred in most of the major taxa (Fig. 4, top). To the water depth of some $30 \mathrm{~m}$, polychaetes were richest in individuals until Phoronis muelleri numerically dominated the assemblage in greater depths (included in 'others' in Fig. 4). Molluscs and echinoderms also increased with depth while crustaceans made an exception. The amphipod Bathyporeia pelagica kept crustacean abundance on a high level close to the beach, while Urothoe poseidonis caused high abundance between 20 and $35 \mathrm{~m}$ depth. As a result, there was no significant correlation between crustacean abundance and depth during most of the sampling periods, and in July 2007 the correlation was even negative (Table 4). The same occurred for polychaete abundance in July 2006. According to the regression coefficients, water depth affected crustaceans and polychaetes the least and 'other taxa' (numerically dominated by $P$. muelleri) the most (Table 4).

With respect to relative abundance, the fauna changed from a $P$. muelleri-dominated association in $>25 \mathrm{~m}$ depth towards polychaete domination in the shallows (Fig. 4, middle). Between 10 and $15 \mathrm{~m}$ depth, molluscs (particularly razor clams Ensis americanus) attained a high proportion of abundance. Towards the beach, crustaceans (mainly highly mobile amphipods) continuously increased their proportions of abundance and became codominant with polychaetes $<8 \mathrm{~m}$ water depth (Fig. 4).

Seasonally, the August patterns were similar to the autumn (September) data though the increments in abundance with depth were less pronounced in August (Fig. 5). In July the increase in abundance with depth was weak (year 2007) or absent (year 2006) in polychaetes (Fig. 5; Table 4). In July 2007 echinoderms were unusually abundant in $20-30 \mathrm{~m}$ depth, and they were exceptionally abundant in July and August 2006 even in low water depth (Fig. 5). These high values were mainly caused by juvenile Echinocardium cordatum. Juveniles also caused exceptional mollusc abundances in July 2006 (Fig. 5). Thus, in some taxa abundance changes along the depth gradient were less pronounced or even reversed during summer recruitment.

\section{Species density}

The number of species per core showed a rather linear increase from the beach to about $30 \mathrm{~m}$ depth and a constant level between 30 and $45 \mathrm{~m}$ (all sampling periods; Fig. 4, bottom). Over time, the coastal depth limit calculated from species density varied between 20 and $31 \mathrm{~m}$ (Fig. 6) and was in most sampling periods identical or very close to the coastal depth limit estimated from abundance data (Fig. 2). However, the coastal depth limit of species density did not correlate significantly with the frequency of waves $>3 \mathrm{~m}$ in June as had been found for the coastal depth limit from abundance data. Instead, the coastal depth limit of species density correlated significantly with the frequency of waves $>2.5 \mathrm{~m}$ in July $\left(r^{2}=0.7013, \quad n=8, \quad t=3.7534\right.$, $p<0.01)$.

The patterns of increase in species density with depth were similar in all major taxa except crustaceans and in all cases paralleled the respective abundance patterns (Fig. 4). This is a consequence of a high correlation between the number of species and individuals per core (Table 5), which explains far more of the variance in species density than depth, sampling period or sediment composition (Table 6, eta-squared). Thus, the landward decrease in species density per unit area is mainly caused by decreasing abundance.
Table 3 ANCOVA of benthos abundance in the years 2006 and 2007 with three sampling periods each (July, August and September)

Model multiple $R^{2}=0.3097$

\begin{tabular}{lcrcrrr}
\hline Effect & Sum of squares & $d f$ & Mean square & \multicolumn{1}{l}{${ }^{2}$} & \multicolumn{1}{l}{$p$} & $\eta^{2}$ \\
\hline Constant & 258.498 & 1 & 258.498 & $1,150.86$ & 0.0000 & 0.3096 \\
Depth & 139.473 & 1 & 139.473 & 620.95 & 0.0000 & 0.1671 \\
Year & 25.243 & 1 & 25.243 & 112.38 & 0.0000 & 0.0302 \\
Month & 14.388 & 2 & 7.194 & 32.03 & 0.0000 & 0.0172 \\
Year $\times$ month & 2.653 & 2 & 1.326 & 5.91 & 0.0028 & 0.0032 \\
Error & 394.646 & 1,757 & 0.225 & & & 0.4727 \\
\hline
\end{tabular}



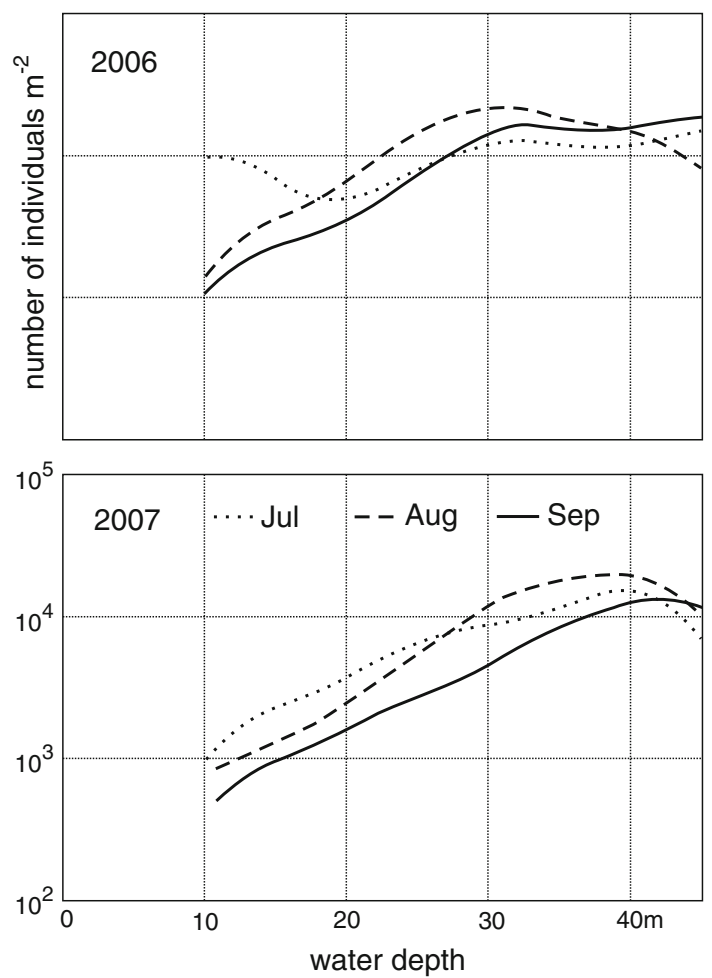

Fig. 3 Seasonal abundance variations in 2006 (top) and 2007 (bottom). Distance-weighted least squares of log-transformed data

Species richness and diversity

Species richness (Fig. 7, left) was less variable along the coastal gradient than species density. The number of species per $1,000(5,000$ or 10,000$)$ individuals was already high close to the beach and increased moderately only to a depth of some $20 \mathrm{~m}$. Between 30 and $40 \mathrm{~m}$, species richness was depressed (Fig. 7). At the same time, abundance attained high or maximum values (Fig. 2). This was caused by mass development of a few species between 30 and $40 \mathrm{~m}$ depth (particularly P. muelleri, occasionally Spiophanes bombyx, Owenia fusiformis or E. cordatum).

The numerical dominance of a few species also resulted in a low Shannon-Wiener diversity index $\mathrm{H}^{\prime}$ between 30 and $40 \mathrm{~m}$ while diversity was at a high and relatively constant level in $<20 \mathrm{~m}$ depth (Fig. 7, right). Thus, species richness and diversity $\mathrm{H}^{\prime}$ showed similar patterns and were highly correlated (Table 7). The entire gradient, species richness and diversity correlated negatively with depth. In species richness, the correlation with depth was weak $\left(r^{2}<0.05\right)$ and significant only in small groups (species per 1,000 individuals) with a high number of cases (Table 7). Temporally, only six out of 12 sampling periods showed a significant correlation between species richness and depth, and in five of the six cases, the correlation was negative (Table 8). Only in July 2006, the correlation was positive, i.e. species richness increased with depth.
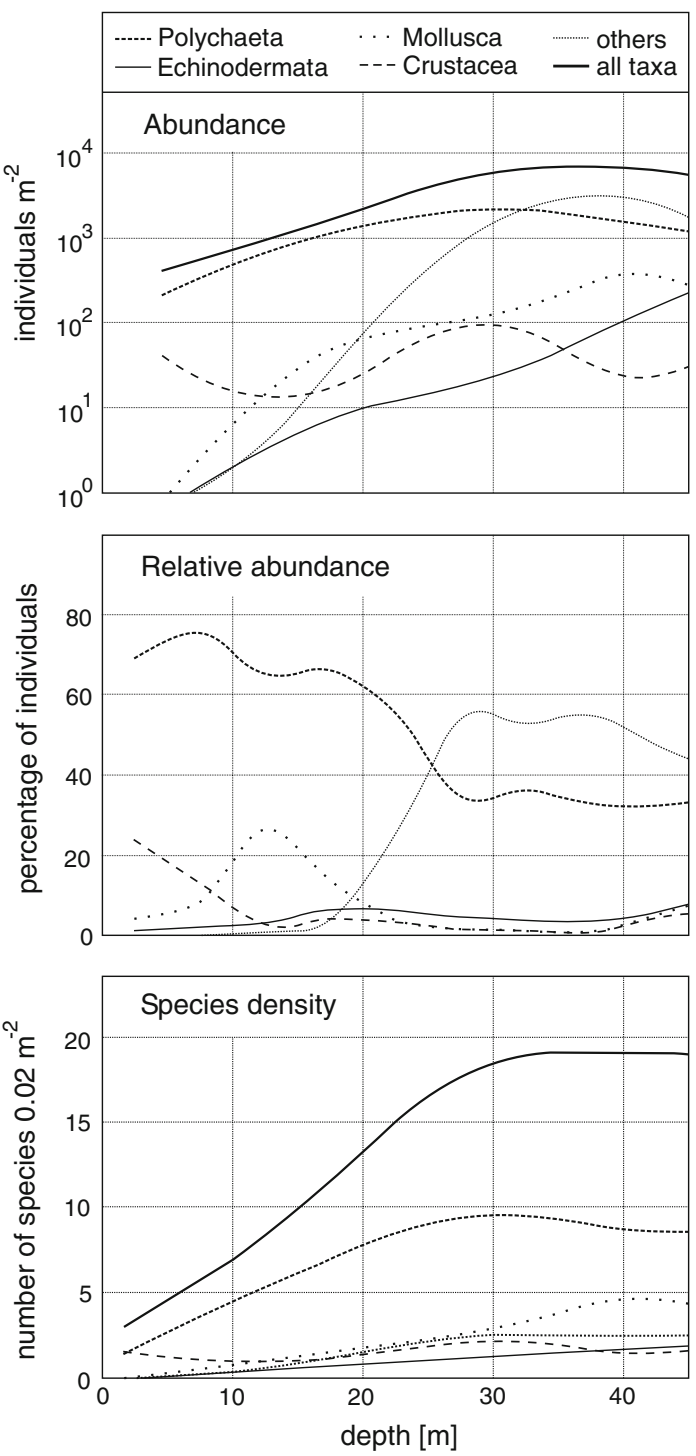

Fig. 4 Abundance in autumn (top), partitioning of abundance (middle) and species density of major taxa (bottom), all years. Distance-weighted least squares

\section{Change of species composition}

During the 17 cruises between 2004 and 2011, 198 out of a total of 334 species have been recorded in $>40 \mathrm{~m}$ depth. Towards shallow waters, most of these species got lost (i.e. they were no longer recorded along the gradient from deep to shallow waters) and only 41 of the 'deep-water' species (approximately $20 \%$ ) occupied the entire coastal gradient (Fig. 8). Most of the species that vanished between 40 and $30 \mathrm{~m}$ can be classed with either an A. filiformis (muddy very fine sand) or a $N$. nitidosa (clayey silt) association. Both associations only occurred at $>40 \mathrm{~m}$ depth in the studied area. However, the largest losses of species occurred between 20 and $5 \mathrm{~m}$ and included all faunal components. 
Table 4 Regression coefficients $\left(R^{2}\right.$, corrected for $d f$ ) of abundance and species density of major taxa and water depth correlations; $* p<0.05$, $* * p<0.01, * * * p<0.001$

\begin{tabular}{|c|c|c|c|c|c|}
\hline & Crustacea & Echinodermata & Mollusca & Polychaeta & Other taxa \\
\hline \multicolumn{6}{|c|}{ Abundance } \\
\hline Sep 04 & 0.008 & $0.169 * * *$ & $0.221 * * *$ & 0.000 & $0.273 * * *$ \\
\hline Oct 05 & $0.015^{*}$ & $0.087 * * *$ & $0.274 * * *$ & $0.085^{* * *}$ & $0.564 * * *$ \\
\hline Jul 06 & 0.000 & $0.119 * * *$ & 0.000 & $0.018^{*}$ & $0.476^{* * *}$ \\
\hline Aug 06 & $0.021 * *$ & $0.050 * * *$ & $0.183 * * *$ & $0.021 * *$ & $0.354 * * *$ \\
\hline Sep 06 & $0.069 * * *$ & $0.154 * * *$ & $0.197 * * *$ & $0.095 * * *$ & $0.471 * * *$ \\
\hline Jul 07 & $0.012 *$ & $0.138 * * *$ & $0.041 * * *$ & $0.124 * * *$ & $0.480 * * *$ \\
\hline Aug 07 & 0.007 & $0.117 * * *$ & $0.179 * * *$ & $0.234 * * *$ & $0.557 * * *$ \\
\hline Sep 07 & $0.026^{* *}$ & $0.221 * * *$ & $0.154 * * *$ & $0.110 * * *$ & $0.609 * * *$ \\
\hline Sep 08 & 0.000 & $0.150 * * *$ & $0.097 * * *$ & $0.107 * * *$ & $0.344 * * *$ \\
\hline Sep 09 & 0.000 & $0.271 * * *$ & $0.304 * * *$ & $0.182 * * *$ & $0.476 * * *$ \\
\hline Sep 10 & 0.000 & $0.312 * * *$ & $0.143 * * *$ & $0.213 * * *$ & $0.538 * * *$ \\
\hline Oct 11 & 0.000 & $0.258 * * *$ & $0.193 * * *$ & 0.000 & $0.407 * * *$ \\
\hline \multicolumn{6}{|c|}{ Species density } \\
\hline Sep 04 & 0.010 & $0.316^{* * *}$ & $0.229 * * *$ & 0.010 & $0.142 * * *$ \\
\hline Oct 05 & $0.049 * * *$ & $0.090 * * *$ & $0.412 * * *$ & $0.083 * * *$ & $0.284 * * *$ \\
\hline Jul 06 & $0.012 *$ & $0.096 * * *$ & $0.269 * * *$ & $0.040 * * *$ & $0.175 * * *$ \\
\hline Aug 06 & $0.059 * * *$ & $0.103 * * *$ & $0.293 * * *$ & $0.023 * *$ & $0.120 * * *$ \\
\hline Sep 06 & $0.102 * * *$ & $0.180 * * *$ & $0.274 * * *$ & $0.090 * * *$ & $0.141 * * *$ \\
\hline Jul 07 & 0.000 & $0.101 * * *$ & $0.151^{* * *}$ & $0.040 * * *$ & $0.237 * * *$ \\
\hline Aug 07 & $0.039 * * *$ & $0.187 * * *$ & $0.272 * * *$ & $0.139 * * *$ & $0.331 * * *$ \\
\hline Sep 07 & $0.095 * * *$ & $0.228 * * *$ & $0.271 * * *$ & $0.253 * * *$ & $0.336 * * *$ \\
\hline Sep 08 & 0.003 & $0.139 * * *$ & $0.187 * * *$ & $0.126^{* * * *}$ & $0.138 * * *$ \\
\hline Sep 09 & $0.011^{*}$ & $0.264 * * *$ & $0.371 * * *$ & $0.361 * * *$ & $0.479 * * *$ \\
\hline Sep 10 & $0.039 * * *$ & $0.288 * * *$ & $0.398 * * *$ & $0.397 * * *$ & $0.465 * * *$ \\
\hline Oct 11 & $0.015^{*}$ & $0.242 * * *$ & $0.313 * * *$ & $0.064 * * *$ & $0.239 * * *$ \\
\hline
\end{tabular}

The 'gains' (=first record along the gradient from deep to shallow waters) showed three peaks (Fig. 8). Some of the 50 additional species that occurred between 40 and $30 \mathrm{~m}$ were coarse sand species as typical for the Goniadella-Spisula association which was rare in $>40 \mathrm{~m}$ depth. However, the major part of these gains may be due to differential sampling effort in different depths, i.e. 1,028 samples from 30 to $40 \mathrm{~m}$ depth as opposed to 193 samples from $>40 \mathrm{~m}$ depth.

The gains between 30 and $10 \mathrm{~m}$ depth can be attributed to two associations, a fauna typical for sandy beaches (e.g. the polychaete Scolelepis squamata) and a faunal component more typical for sheltered areas like the Wadden Sea behind the barrier islands (e.g. the bivalves Cerastoderma edule and Macoma balthica, or the polychaete Pygospio elegans). Finally, the gains in $<10 \mathrm{~m}$ depth were limited to a few specialists for turbulent beaches such as the amphipod Haustorius arenarius.

MDS indicated that community composition strongly depends upon sediment composition and water depth (Fig. 9). Dimension 1 largely reflected sediment composition and arranged fine sand species to the left, coarse sand species to the right, and less sediment-dependent species in between. Dimension 2 had a strong load of water depth and arranged the species restricted to deeper water to the bottom and those that are abundant in shallow water to the top of Fig. 9. With respect to faunal associations, the muddy very fine sand $A$. filiformis association and the clayey silt $N$. nitidosa association both appear in the lower left of the diagram (fine sediment/deep water). The coarse sand Goniadella-Spisula association takes the right side of Fig. 9 and the fine sand T. fabula association the centre and the upper left. However, the scatter of data points is rather even without gaps between these assemblages. This indicates a continuous shift of community composition.

The lack of species in the top left of Fig. 9 coincides with the lack of mud and very fine sand in the shallow $(>10 \mathrm{~m})$ part of the study area. Similarly, coarse sand rarely occurred in $>40 \mathrm{~m}$ depth, explaining the lack of data points in the lower right of the diagram. However, the lack of species in shallow-water coarse sand may be an artefact of condensing our data to the 80 most abundant species: coarse sand shallow water species were not frequent enough to be included in this analysis. Thus, the position of individual species in the MDS ordination may be interpreted as an 
Fig. 5 Abundance of major taxa during summer 2006 and 2007; distance-weighted least squares of log-transformed data
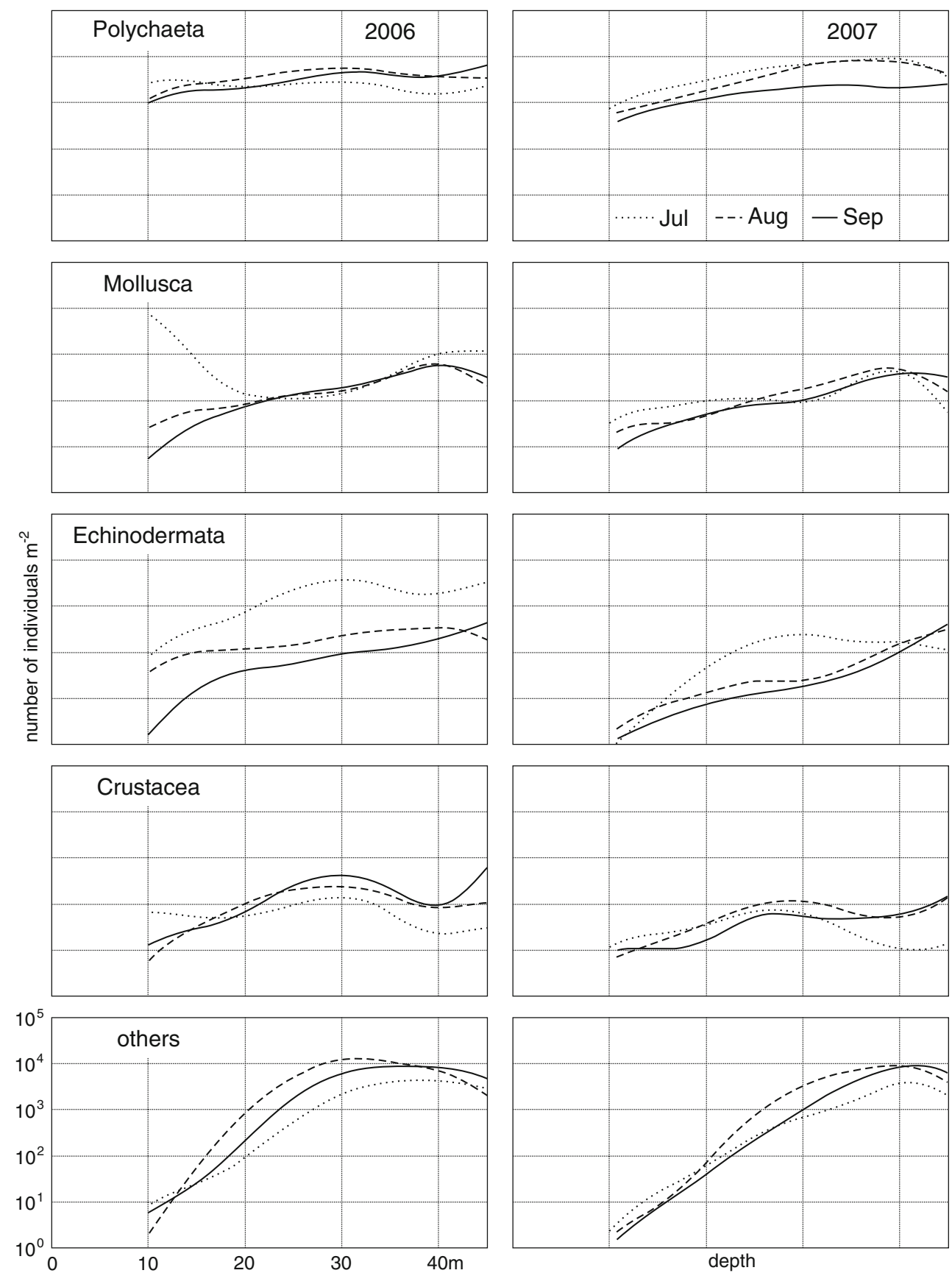

indicator of the realised niche (with respect to sediment composition and water depth) within the restrictions set by the local availability of sediment types.

\section{Discussion}

The swash exclusion hypothesis (McLachlan et al. 1984) and its subtidal extension, the WEH (Paavo et al. 2011), predict that benthic communities increase in richness, density, total abundance and biomass with decreasing wave energy. In the south-eastern North Sea, mean shear stress velocity driven by wind-induced waves enables resuspension of particulate matter over all of our study areas during storm periods and down to approximately $10 \mathrm{~m}$ during calm periods (Dobrynin et al. 2010). The currents component does not differ significantly during the calm and the storm periods and shows permanent resuspension zones in the shallowest $(<10 \mathrm{~m})$ waters (Dobrynin et al. 2010). From this we conclude that the sediments in shallow $(<10 \mathrm{~m})$ waters experience disturbance by both waves and currents (the latter occurring regularly in some parts of the 

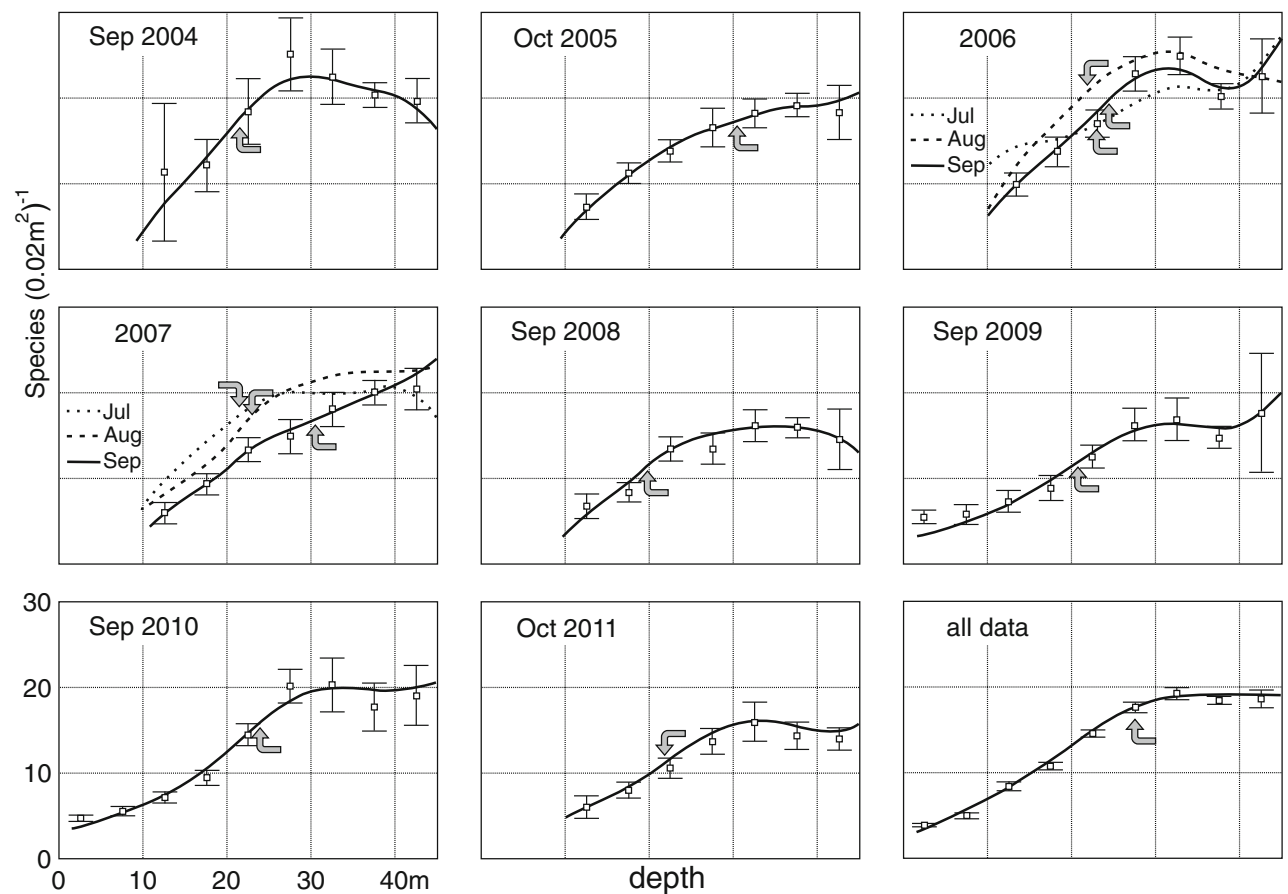

Fig. 6 Temporal variability in macrobenthic species density; mean $\pm 95 \%$ confidence intervals (horizontal bars, for September and October data only) and distance-weighted least squares (line). Arrows indicate the coastal depth limit as estimated by ANOVA

Table 5 Correlations $\left(r^{2}\right)$ between the number of species per core, abundance (log-transformed) and water depth

\begin{tabular}{llll}
\hline Date & $\begin{array}{l}\text { No. of } \\
\text { species } \\
\text { versus depth }\end{array}$ & $\begin{array}{l}\text { Abundance } \\
\text { versus depth }\end{array}$ & $\begin{array}{l}\text { No. of species } \\
\text { versus } \\
\text { abundance }\end{array}$ \\
\hline Apr 2004 & 0.2849 & 0.2671 & 0.6839 \\
Sep 2004 & 0.1657 & 0.1471 & 0.6714 \\
Oct 2005 & 0.3276 & 0.3255 & 0.6359 \\
Jul 2006 & 0.1909 & 0.0763 & 0.4091 \\
Aug 2006 & 0.1907 & 0.2030 & 0.5457 \\
Sep 2006 & 0.2572 & 0.3297 & 0.6088 \\
Jul 2007 & 0.1324 & 0.2133 & 0.7296 \\
Aug 2007 & 0.3155 & 0.3844 & 0.6802 \\
Sep 2007 & 0.4029 & 0.4119 & 0.6720 \\
Sep 2008 & 0.2054 & 0.2695 & 0.6003 \\
Sep 2009 & 0.2345 & 0.1832 & 0.7052 \\
Sep 2010 & 0.3386 & 0.1183 & 0.5228 \\
Oct 2011 & 0.2291 & 0.1383 & 0.7114 \\
All data & 0.3654 & 0.3195 & 0.6963 \\
\hline
\end{tabular}

Due to the high number of cores per date, all correlations are highly significant $(p<0.0001)$

study area and frequently in others, Dobrynin et al. 2010). In deeper waters, waves dominate hydrographic sediment disturbance, with waves of increasing energy reaching down to increasing water depth. The combined effect of waves and currents results in a potential for physical sediment disturbance decreasing with increasing water depth.
Therefore, for our study area the WEH predicts that benthic communities generally increase in richness, density, total abundance and biomass with increasing water depth until a depth is reached, where wave effects become too weak to significantly affect community composition. We call this depth the 'coastal depth limit'. Since both the frequency and intensity of storms vary over seasons, the water depth with significant sediment disturbance may vary in the short term temporally. However, the coastal depth limit is expected to vary less because the effects of a single storm may engrave on community composition for many months, depending on the life cycles of the species. Accordingly, local community composition may reflect a history of many storm-driven disturbance events with a low chance to isolate a single storm causing a particular spatial pattern.

As was predicted from the WEH, total abundance and species richness both increased with increasing water depth. Over time, the coastal depth limit varied between 20 and $31 \mathrm{~m}$, and during most sampling periods, the same depth limits derived from abundance and species density. Seaward of the coastal depth limit, the least-square estimates of abundance and species density continued to increase, but ANOVAs failed to detect significant differences among these deeper water stations. In part, this is due to the strong variability in the data, particularly on small spatial scales, as seems to be typical for shallow coastal waters (Chapman et al. 2010). We therefore assume that our estimates of the coastal depth limit are rather 
Table 6 ANCOVA of species density depending on depth, abundance, cruise and median diameter of sand grains (sediment md); model multiple $R^{2}=0.7105$

\begin{tabular}{lcrrrrr}
\hline Effect & Sum of squares & \multicolumn{1}{c}{$d f$} & Mean square & \multicolumn{1}{c}{$F$} & \multicolumn{1}{l}{$\eta^{2}$} \\
\hline Constant & $31,630.45$ & 1 & $31,630.45$ & $1,935.18$ & 0.0000 & 0.1922 \\
Depth & $3,282.97$ & 1 & $3,282.97$ & 200.92 & 0.0000 & 0.0200 \\
Sediment md & 448.42 & 1 & 448.42 & 27.44 & 0.0000 & 0.0027 \\
Abundance & $65,692.46$ & 1 & $65,692.46$ & $4,020.41$ & 0.0000 & 0.3992 \\
Cruise & $2,583.84$ & 12 & 215.32 & 13.18 & 0.0000 & 0.0157 \\
Error & $60,914.54$ & 3,728 & 16.34 & & & 0.3702 \\
\hline
\end{tabular}

conservative while wave effects may proceed further offshore but are masked by strong small-scale variability. The temporal variation in the coastal depth limit in autumn correlated positively with the frequency of waves $>3 \mathrm{~m}$ in June (for abundance) with the frequency of waves $>2.5 \mathrm{~m}$ in July (for species density). Although these correlations were not very convincing (for the reasons see the 'Methods' section), their mere existence corroborates the WEH. According to the arguments above, a temporal delay between a storm event and the detection of its possible effects does not contradict the WEH.

Further support for wave energy as the main driving factor for these coastal gradients comes from seasonal comparisons. In July 2006 we observed exceptional high densities of juvenile echinoderms and molluscs even in shallow waters while abundances showed rather normal curves in August and September. This coincided with a 4-week calm period prior to the July sampling (no waves $>2 \mathrm{~m}$ ). In 2007 abundance of all taxa was low in the shallows from July onwards, which coincided with stormy weather 1 week prior to the July sampling with waves exceeding $3 \mathrm{~m}$ height.

High abundance of juveniles in early summer supports the idea that recruitment limitation was less important for the establishment of spatial patterns than post-settlement processes (Olafsson et al. 1994) and wave disturbance may be a prominent factor for juvenile survival (Paavo et al. 2011; possibly replaced by ice disturbance in Arctic coasts, Smale 2008). Since we expect species-specific correlations between individual size and the susceptibility to sediment disturbance, the timing of a summer storm may be as important as its intensity. In addition, the potential for recovery varies with the availability of adults, post-larvae and larvae (Norkko et al. 2010). Therefore, we suggest that climate-driven changes in the timing of summer storms may change this coastal community without changes in storm frequency or intensity.

Snelgrove and Butman (1994) proposed that the decrease in wave energy with depth allows increasingly more species to establish with an increasing potential for biological control of sediment characteristics. During our study, species richness did only significantly increase with depth in July 2006 (Table 7), which coincided with a 4-week period of exceptionally calm weather, i.e. a low potential for wave control of the benthos. During half of the sampling periods, we found no significant correlation between species richness and depth, while there were five sampling periods where species richness significantly decreased with depth (Table 7). Thus, the WEH is not supported for species richness, and since species richness strongly correlated with $\mathrm{H}^{\prime}$, this is also true for Shannon-Weaver diversity. However, these conclusions are only true for the entire gradient of water depth, i.e. 2-45 m. Between 2 and $20 \mathrm{~m}$, species richness per 1,000 individuals indeed increased rather steadily (Fig. 7). The decreases in species richness between 20 and $40 \mathrm{~m}$ were due to $P$. muelleri as a super-abundant species and to highly abundant juveniles of a few other species. Therefore, the depression of species richness between 20 and $40 \mathrm{~m}$ may be special to the season studied here (summer and autumn) but less developed in winter and spring. The potential for biological control of sediment characteristics (Snelgrove and Butman 1994) may nevertheless increase with increasing depth during all seasons, but this may be due to higher abundances, not more species (Murray et al. 2002). Therefore, the maximum water depth with a significant wave-induced change in faunal composition depends on the abundance and specific composition of the faunal assemblage (Davis 1993), particularly with respect to sediment stabilising or destabilising species (Borsje et al. 2008). It remains to be tested whether this depth can be sufficiently predicted for the shelf by easy-to-model physical factors such as shear stress. In the Wadden Sea adjoining to our study area, hydrodynamic variables predicted benthic community structure significantly better than sediment variables (Puls et al. 2012).

Although the WEH was corroborated for abundance and species richness of total benthos, there are differences among taxa. Particularly, crustacean and polychaete abundances showed less variation along the depth gradient than the other taxa (Figs. 4, 5). Differences in physiology and morphology, swimming and burrowing abilities, and the way of reproduction may all contribute to these differences. However, the differences among taxa were less distinct for species density.

The faunal composition changed continuously over the studied gradient of water depth. It included species from three faunal assemblages: 
Fig. 7 Species richness (left) and diversity $\mathrm{H}^{\prime}$ (right) for the groups of 1,000, 5,000 and 10,000 individuals, all sampling dates. Not all data points visible. The lines are distance-weighted least squares
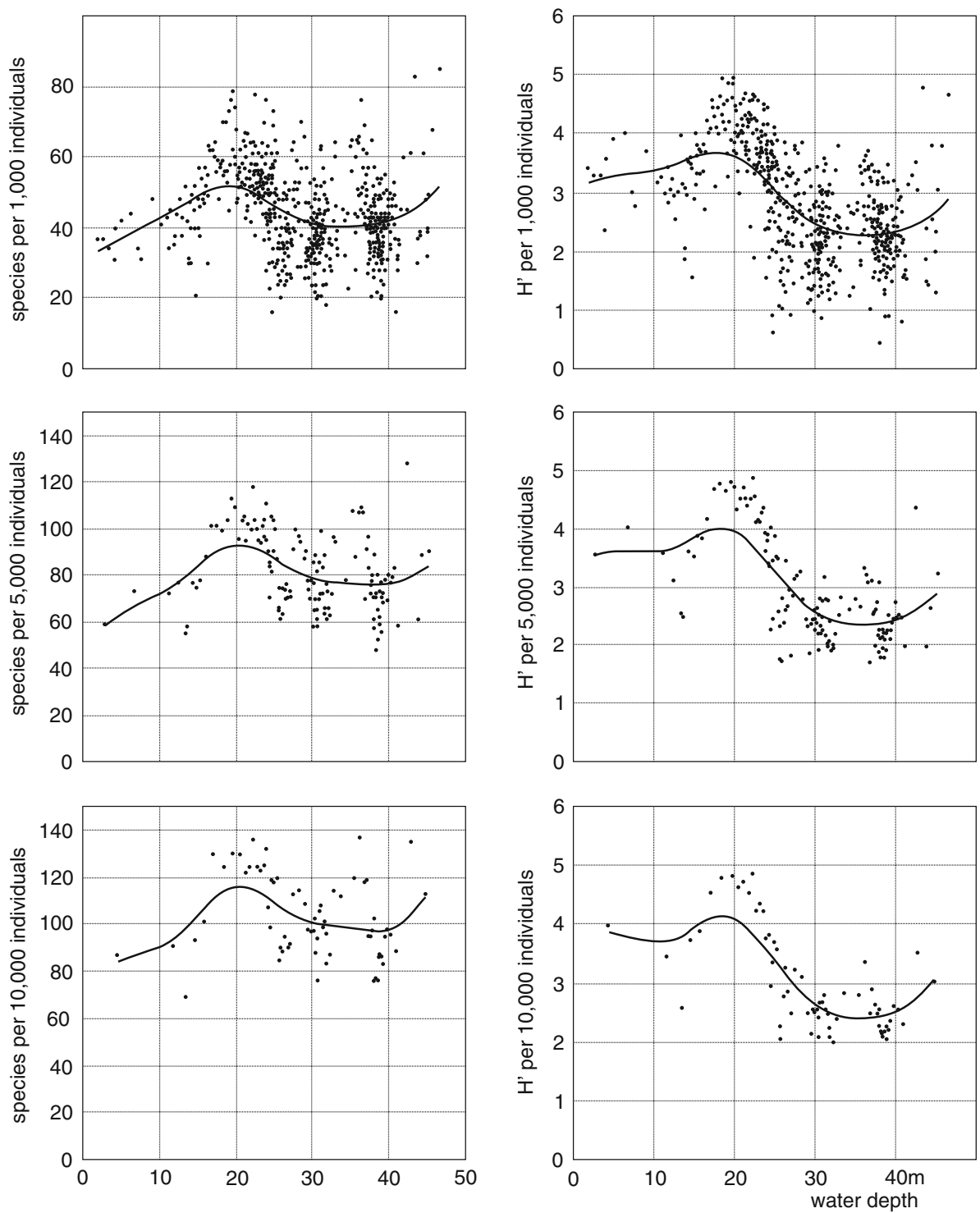

Table 7 Correlations between species richness, diversity $\mathrm{H}^{\prime}$ and water depth (all data)

\begin{tabular}{|c|c|c|c|c|c|c|}
\hline \multirow{3}{*}{$\begin{array}{l}\text { Group size } \\
\text { No. of cases }\end{array}$} & \multicolumn{2}{|l|}{1,000} & \multicolumn{2}{|l|}{5,000} & \multicolumn{2}{|l|}{10,000} \\
\hline & \multicolumn{2}{|c|}{$N=540 *$} & \multicolumn{2}{|c|}{$N=134$} & \multicolumn{2}{|c|}{$N=67$} \\
\hline & $r^{2}$ & $p$ & $r^{2}$ & $p$ & $r^{2}$ & $p$ \\
\hline Species richness versus $\mathrm{H}^{\prime}$ & 0.7080 & 0.0000 & 0.5911 & 0.0000 & 0.5337 & 0.0000 \\
\hline Species richness versus depth & 0.0415 & 0.0000 & 0.0441 & 0.0149 & 0.0327 & 0.1428 \\
\hline $\mathrm{H}^{\prime}$ versus depth & 0.2511 & 0.0000 & 0.3662 & 0.0000 & 0.4154 & 0.0000 \\
\hline
\end{tabular}

* Cores with $>1,000$ individuals excluded

1. Species living in deeper parts of the North Sea became increasingly suppressed in abundance in the shallows, presumably due to the relatively harsh physical conditions. Nevertheless, some of these deeper living species numerically dominated in the shallows because they were less affected by hydrodynamic disturbance than many others although their abundance in the shallows was far less than in deeper waters. Thus, dominance in a marginal habitat does not necessarily indicate species-specific optimal conditions. 
Table 8 Temporal variation in correlations between species richness (species per 1,000 individuals) and water depth

\begin{tabular}{llll}
\hline Date & $r$ & $r^{2}$ & $p$ \\
\hline Sep 2004 & -0.2032 & 0.0413 & 0.3094 \\
Oct 2005 & -0.5030 & 0.2530 & $\mathbf{0 . 0 0 0 8}$ \\
Jul 2006 & +0.2960 & 0.0876 & $\mathbf{0 . 0 1 2 2}$ \\
Aug 2006 & -0.1420 & 0.0202 & 0.1653 \\
Sep 2006 & -0.3818 & 0.1458 & $\mathbf{0 . 0 0 0 7}$ \\
Jul 2007 & -0.5692 & 0.3240 & $\mathbf{0 . 0 0 0 0}$ \\
Aug 2007 & -0.5565 & 0.3097 & $\mathbf{0 . 0 0 0 0}$ \\
Sep 2007 & -0.6673 & 0.4453 & $\mathbf{0 . 0 0 0 0}$ \\
Sep 2008 & -0.3191 & 0.1018 & 0.0617 \\
Sep 2009 & +0.3040 & 0.0924 & 0.0565 \\
Sep 2010 & +0.1358 & 0.0184 & 0.3911 \\
Oct 2011 & -0.3515 & 0.1226 & 0.1181 \\
\hline
\end{tabular}

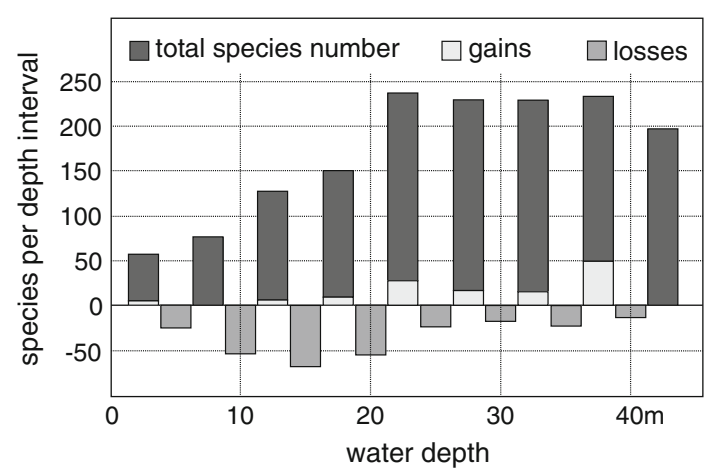

Fig. 8 Change of species number in 5-m depth intervals from deep towards shallow waters. 'Losses' are species that occurred in the neighbouring right (deeper) water level but were no more recorded in the inspected water level. 'Gains' are species not recorded in deeper water levels but present in the inspected level
2. The second faunal assemblage contributing species to the study area was the beach face and adjoining turbulent zone. However, as abundance of these species was already low in their home ranges, their contribution to species richness was low and their contribution to abundance negligible.

3. Finally, quite a high number of species from the shallow (10-25 m) part of the studied area are common in the Wadden Sea just behind the North Frisian barrier islands. Compared to the sheltered Wadden Sea, their abundances in the North Sea were very low, possibly too low to form self-sustaining populations. We assume many of these individuals arrived from the adjoining Wadden Sea. Therefore, the gradient of species richness may look different in exposed coastal sections far from such a sheltered source pool.

MDS indicated a continuous change of community composition, with sediment composition as a prominent factor. At the same time, ANCOVA gave the impression that sediment composition was a marginal factor only. Two facts may contribute to this apparent contradiction. On the one hand, median grain size decreased rather regularly with increasing depth, from coarse sand close to the beach to fine sand with increasing amounts of silt in deeper water. Therefore, sediment composition and water depth are not independent factors and water depth as a covariant in ANCOVA already included this general trend in sediment composition. We assume that median grain size only accounted for the small-scale spatial differences in sediment composition in these ANCOVAs. Excluding water depth from the ANCOVAs increased the importance of sediment composition but at the price of a distinct
Fig. 9 nMDS ordination plot of abundant species; for clearness, only half of the species are named (filled dots)

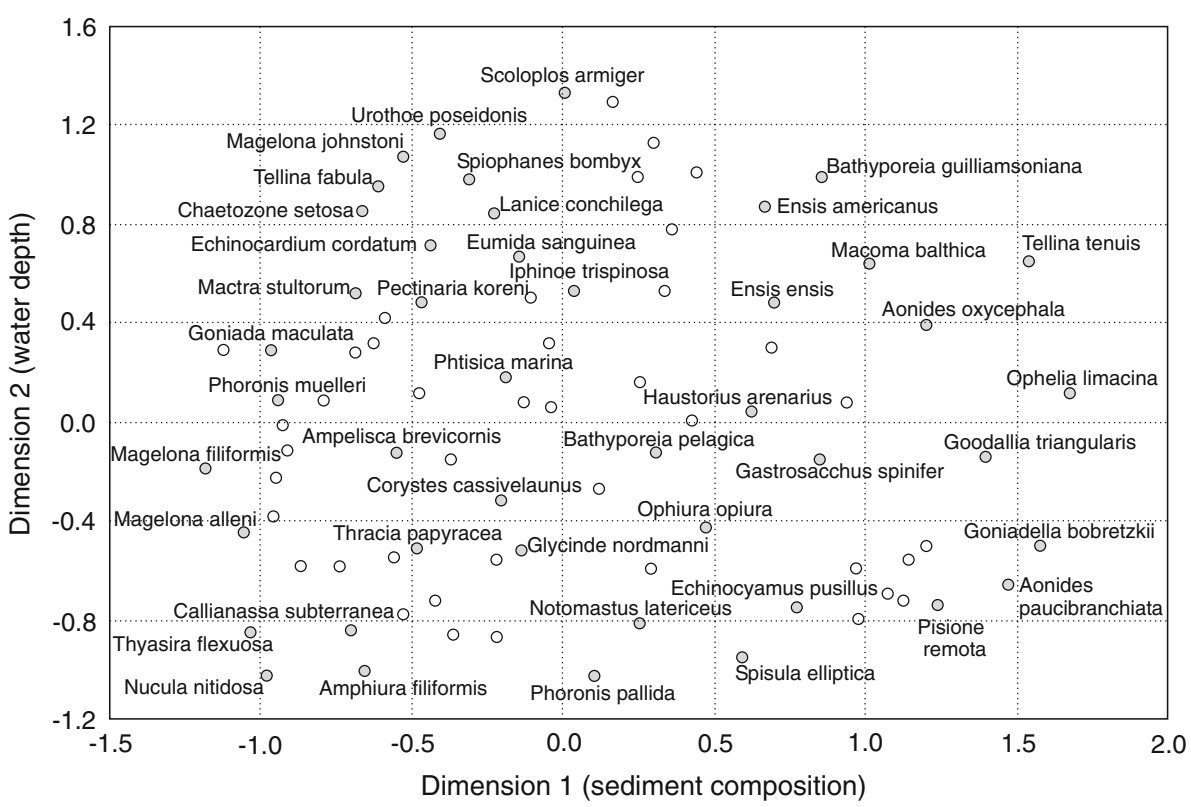


reduction in model fit. On the other hand, these ANCOVAs estimated the effects of water depth and sediment composition on total benthos abundance and total species richness (i.e. at the level of communities) while MDS was based on abundance of single species.

Our results for abundance and species density of total benthos are in accordance with SEH, but there are deviations on the level of major taxa. For species richness and diversity index $\mathrm{H}^{\prime}$, SEH is only supported for the shallowest $(<20 \mathrm{~m})$ part of the study area. From the observed seasonal effects, we suggest that exposed sandy coasts are initially colonised by an abundant and species-rich community of juveniles arriving as larvae (or post-larvae, Turner et al. 1997) from all surrounding habitats within reach, without major spatial variation in abundance or species richness. The depth gradients of species density and abundance consistently found in autumn develop during early summer (i.e. shortly after juvenile settlement). According to SEH, removal or mortality of juveniles by wave- and current-induced disturbance of the sediment is one mechanism, but because species differ in susceptibility to these disturbances, other species may benefit from (wave-mediated) release from competitors or predators. The intensity of sediment disturbance varies with depth and wave energy, while the intensity of the disturbance effect on the benthos additionally depends on the timing of disturbance. In the studied part of the North Sea, the depth limit of statistically significant disturbance effects on the benthos varied between 20 and $31 \mathrm{~m}$ (exceptional storms did not occur during the study period). Based on bathymetry, this equals a breadth of the coastal zone of $40-80 \mathrm{~km}$ off the chain of barrier islands.

Acknowledgments Many thanks are due to the crews of RV Heincke and Oland and to the numerous students helping to collect and process the thousands of samples on board. Frerk Jensen (Landesbetrieb für Küstenschutz, Nationalpark und Meeresschutz SchleswigHolstein, Husum) kindly provided the Westerland wave rider buoy data. Special thanks are due to two anonymous reviewers for their extremely detailed comments.

Conflict of interest The authors declare that they have no conflict of interest.

\section{References}

Borsje BW, de Vries MB, Hulscher SJMH, de Boer GJ (2008) Modeling large-scale cohesive sediment transport affected by small-scale biological activity. Estuar Coast Shelf Sci 78:468-480

Brown AC, McLachlan A (1990) Ecology of sandy shores. Elsevier, Amsterdam

Chapman MG, Tolhurst TJ, Murphy RJ, Underwood AJ (2010) Complex and inconsistent patterns of variation in benthos, micro-algae and sediment over multiple spatial scales. Mar Ecol Prog Ser 398:33-47
Davis WR (1993) The role of bioturbation in sediment resuspension and its interaction with physical shearing. J Exp Mar Biol Ecol 171:187-200

Defeo O, McLachlan A (2005) Patterns, processes and regulatory mechanisms in sandy beach macrofauna: a multi-scale analysis. Mar Ecol Prog Ser 295:1-20

Diesing M, Kubicki A, Winter C, Schwarzer K (2006) Decadal stability of sorted bedforms, German Bight, southeastern North Sea. Cont Shelf Res 26:902-916

Dobrynin M, Gayer G, Pleskachevsky A, Günther H (2010) Effect of waves and currents on the dynamics and seasonal variation of suspended particulate matter in the North Sea. J Mar Syst 82:1-20

Gotelli NJ, Colwell RK (2001) Quantifying biodiversity: procedures and pitfalls in the measurement and comparison of species richness. Ecol Lett 4:379-391

Gray JS (2002) Species richness of marine soft sediments. Mar Ecol Prog Ser 244:285-297

Hall SJ (1994) Physical disturbance and marine benthic communities: life in unconsolidated sediments. Oceanogr Mar Biol Ann Rev 32:179-239

Hulbert SH (1984) Pseudoreplication and the design of ecological field experiments. Ecol Monogr 54:187-211

Janssen G, Kleef H, Mulder S, Tydeman P (2008) Pilot assessment of depth related distribution of macrofauna in surf zone along Dutch coast and its implications for coastal management. Mar Ecol Suppl 29(1):186-194

Le Hir R, Roberts W, Cazaillet O, Christie M, Bassoullet P, Bacher C (2000) Characterization of intertidal flat hydrodynamics. Cont Shelf Res 20:1433-1459

McLachlan A (1990) Dissipative beaches and macrofauna communities on exposed intertidal sands. J Coast Res 6:57-71

McLachlan A, Cockcroft AC, Malan DE (1984) Benthic faunal response to a high energy gradient. Mar Ecol Prog Ser 15:51-63

Morrisey DJ, Howitt L, Underwood AJ, Stark JS (1992) Spatial variation in soft-sediment benthos. Mar Ecol Prog Ser 81:197-204

Murray JMH, Meadows A, Meadows PS (2002) Biogeomorphological implications of microscale interactions between sediment geotechnics and marine benthos: a review. Geomorphology 47:15-30

Norkko J, Norkko A, Thrush SF, Valanko S, Suurkuukka H (2010) Conditional response to increasing scales of disturbance, and potential implications for threshold dynamics in soft-sediment communities. Mar Ecol Prog Ser 413:253-266

Olafsson EB, Peterson CH, Ambrose WG (1994) Does recruitment limitation structure populations and communities of macroinvertebrates in marine soft sediments: the relative significance of pre- and post-settlement processes. Oceanogr Mar Biol Ann Rev 32:65-109

Paavo B, Jonker R, Thrush S, Probert PK (2011) Macrofaunal community patterns of adjacent coastal sediments with wavereflecting or wave-dissipating characteristics. J Coast Res 27(3):515-528

Puls W, van Bernem K-H, Eppel D, Kapitza H, Pleskachevsky A, Riethmüller R, Vaessen B (2012) Prediction of benthic community structure from environmental variables in a soft-sediment tidal basin (North Sea). Helgol Mar Res 66:345-361

Ramey PA, Grassle JP, Grassle JF, Petrecca RF (2009) Small-scale, patchy distributions of infauna in hydrodynamically mobile continental shelf sands: do ripple crests and troughs support different communities? Cont Shelf Res 29:2222-2233

Salzwedel H, Rachor E, Gerdes D (1985) Benthic macrofauna communities in the German Bight. Veröff Inst Meeresforsch Bremerh 20:199-267

Smale DA (2008) Continuous benthic community change along a depth gradient in Antarctic shallows: evidence of patchiness but not zonation. Polar Biol 31:189-198 
Snelgrove PVR, Butman CA (1994) Animal-sediment relationships revisited: cause versus effect. Oceanogr Mar Biol Ann Rev 32:111-177

Somerfield PJ, Gage LD (2000) Community structure of the benthos in Scottish Sea-lochs. IV. Multivariate spatial pattern. Mar Biol 136:1133-1145

StatSoft (1994) STATISTICA for windows (volume II): graphics. StatSoft, Tulsa

Turner SJ, Grant J, Pridmore RD, Hewitt JE, Wilkinson MR, Hume TM, Morrisey DJ (1997) Bedload and water-column transport and colonization processes by post-settlement benthic macrofauna: does infaunal density matter? J Exp Mar Biol Ecol 216:51-75

Ulses C, Estournel C, Durrieu de Madron X, Palanques A (2008) Suspended sediment transport in the Gulf of Lions (NW Mediterranean): impact of extreme storms and floods. Cont Shelf Res 28:2048-2070

Warner JC, Armstrong B, Sylvester CS, Voulgaris G, Nelson T, Schwab WC, Denny JF (2012) Storm-induced inner-continental shelf circulation and sediment transport: Long Bay, South Carolina. Cont Shelf Res 42:51-63 